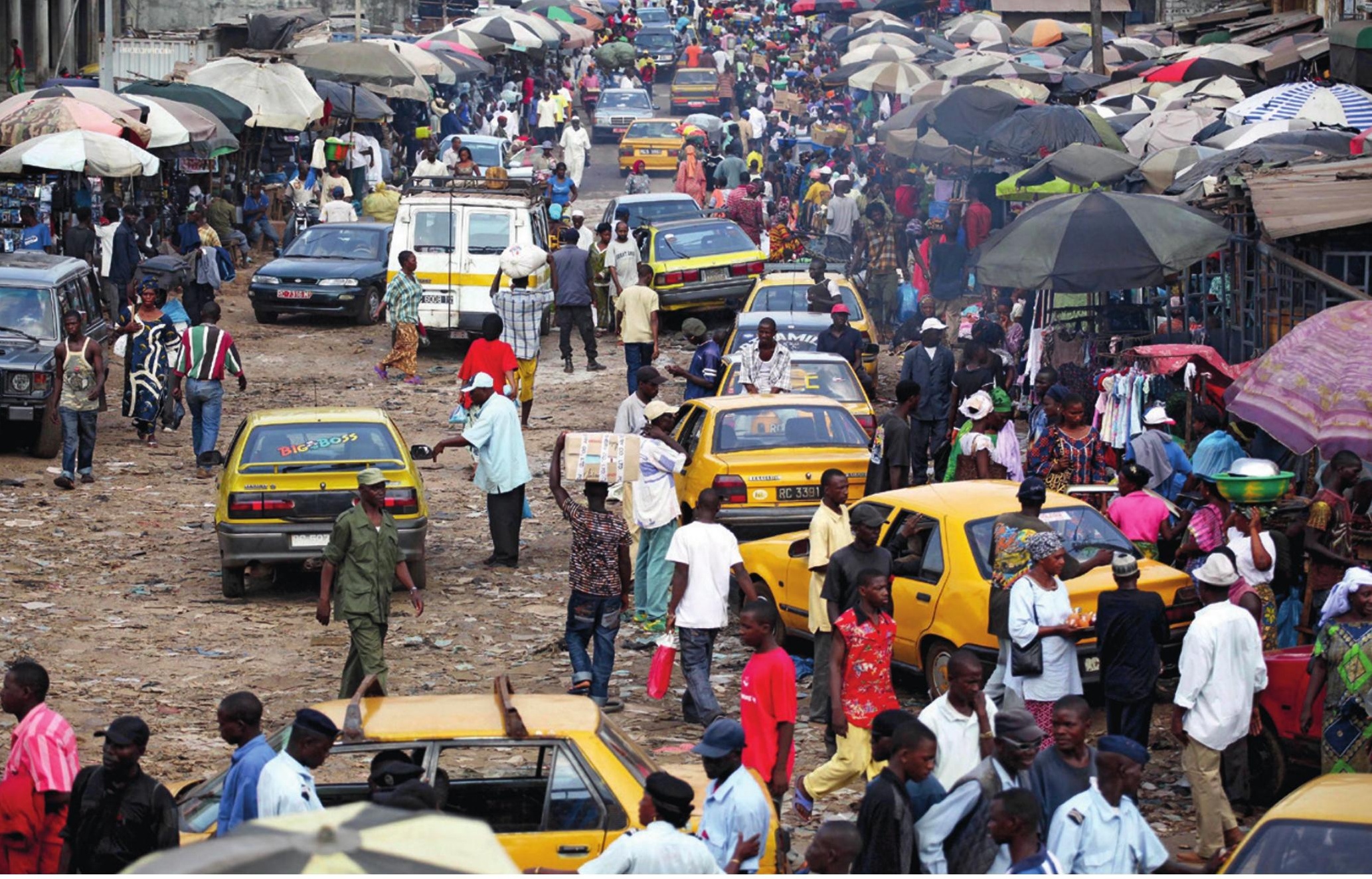

Madina market in Conakry, Guinea. Densely populated urban environments are ideal for the spread of infection.

\title{
DISEASE
}

\section{Poverty and pathogens}

\section{The growth of slums in the developing world's rapidly expanding cities is creating new opportunities for infectious disease to flourish and spread.}

\section{BY MICHAEL EISENSTEIN}

A s Lee Riley read article after article about the deadly 2014 Ebola outbreak, his frustration mounted. "I was seeing all of these newspaper reports and even scientific reports talking about this unprecedented epidemic in West Africa," says Riley, a specialist in urban public health at the University of California, Berkeley, "and there wasn't a single mention of the words 'slums' or 'informal settlements."'

Ebola is feared because of its high mortality and limited treatment options, but generally it has been limited to remote rural regions. The 2014 outbreak was different: flare-ups in cities such as Conakry in Guinea and Monrovia in Liberia revealed the havoc that this lethal virus could wreak in urban environments. The dense and highly mobile populations provided greater

opportunities for the infection to spread. And

according to Mosoka Fallah, an epidemiologist who was working with Liberia’s Ministry of Health at the front line of the Monrovia outbreak, urban slums bore the brunt. "Wherever there were big outbreaks, most people being infected were among the poor," he says. "Those that didn't have basic sanitation, who had the most distrust of institutions - they also had the most disease."

Developing nations have experienced an astonishing boom in urbanization in the past few decades. The urban population of Kenya, for example, has grown at an average rate of $4.3 \%$ per year since 2010 , as rural citizens have moved to cities in pursuit of new opportunities. "The range is between 3\% and 6\% in most of Africa," says Robert Breiman, an infectious-disease epidemiologist at Emory Global Health Institute in Atlanta, Georgia. Riley says that there has been a similar trend in Brazil, where $85 \%$ of the population now lives in cities. Many migrants initially make their home in informal settlements at the city periphery. The United Nations Human
Settlement Programme UN-Habitat estimates that 863 million people - one-third of the developing world's urbanites - live in slums.

Although better access to medical care means that the health of city dwellers across the socioeconomic spectrum is generally superior to that of their rural counterparts, cities can also provide greater opportunities for infectious diseases to flourish. Crowding and poor or non-existent infrastructure exacerbate the risk of infectious disease to slum inhabitants in particular. However, as demonstrated by the rapid spread of the Zika virus over the past year, outbreaks can be a threat to entire cities, nations and - thanks to globalization - the rest of the world.

\section{CLOSE QUARTERS}

Breiman has worked extensively in Kibera, one of the oldest and most established slums in Nairobi. Some attempts have been made to assimilate this area into the capital's infrastructure - with mixed results. "There is piped 
water that comes in, but it is tapped into by local water sellers," he says. The damage they cause to the pipes makes it easy for contamination to occur. "There's a lot of running sewage, and oftentimes it mixes with the corrupted water pipes." Less established slums have no piped water or waste disposal at all.

These conditions are ideal for the spread of diseases such as cholera, a bacterial diarrhoeal infection transmitted through contaminated food and water. "We still have lots of epidemics of cholera in Africa, and these are typically associated with sanitation," says Amadou Sall, an infectious-disease researcher at the Pasteur Institute in Dakar, Senegal. Typhoid infection occurs through a similar route. Children in Kenya's informal settlements have a one in five chance of contracting typhoid by age ten, says Breiman. In his view, this problem is entirely attributable to poor living standards. "When typhoid went away in New York City and London, and elsewhere, it didn't go away because of vaccines," says Breiman. "It went away because there were

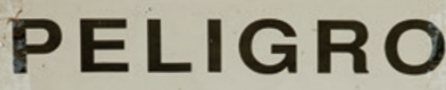
physical changes in these environments, and people were living in a different manner."

The rise of urban Ebola was a product of overcrowding and inadequate medical care, as well as close ties between people who had recently arrived in the city and their home villages. The first case diagnosed in Conakry was contracted at a rural family funeral and only turned symptomatic after the person returned to the city. "When that patient got sick, they went to the hospital and initiated several infections among the health-care workers," says Sall. Instead of going to hospitals, many other people in Conakry went to makeshift medical facilities in spaces that lacked the resources to protect carers or patients, such as peoples' homes; this did more to spread the infection than to contain it. The urban poor often travel far and wide to find work, greatly increasing the area that could be affected by the virus and making contact tracing - finding and monitoring people exposed to infected individuals - a daunting undertaking. "In our latest outbreak, we had over 165 contacts that had spread across almost $60 \%$ of the city," says Fallah.

\section{COUNTRY BUG, CITY BUG}

Unlike Ebola or typhoid, many diseases require an intermediary vector - often an insect - to jump from person to person. For these pathogens, becoming a permanent feature of the urban environment is a protracted process because the vector must first establish a foothold there.

An abrupt shift from an agricultural lifestyle to city living can facilitate this process. Chagas disease, a parasitic infection spread by insects called triatomines, has long plagued rural parts of Latin America. But over the past few decades, it has begun to show up in cities as well. The insects accompany rural migrants - and the parasite-infected animals they bring with them - to mid-altitude cities in the Americas, such as Arequipa in Peru. Here, the primary vehicles for the disease are guinea pigs - a popular staple of the Peruvian diet. The poorest immigrants typically congregate in makeshift, illegal settlements known as invasiones. These poorlyconstructed shanty towns have the makings of an ideal home for triatomines, which like to dwell in wall cracks. But opportunities to feed are greater in areas that are more densely populated than the relatively spartan invasiones. Because of this, it is the equally poor, but more established areas of the city nearby - those that have made the jump from illegal camps to legitimate urban dwelling - that face the worst infestations. Arequipa's invasiones are merely the entry point for the insects. "Once people get their land titles, there's this infusion of building materials, dogs, guinea pigs and other animals, and more people that's the tinderbox that allows the bug to take off," says Michael Levy, an epidemiologist at the University of Pennsylvania in Philadelphia, who has worked in Arequipa for more than a decade. Further improvements to living conditions less crowding, fewer animals and higher-quality homes - seems to be a deterrent to the insects, says Levy.

Whereas triatomines are restricted to certain parts of the Americas, the mosquito Aedes aegypti has become entrenched in cities throughout the tropics, largely driven by Asian and African industrialization. This mosquito, which transmits the viruses responsible for dengue and yellow fever, normally breeds in tiny pools of water such as those found in holes in trees. But the rise of cars and plastics has given A. aegypti appealing new options. "Tires that wear out would get discarded in the environment, and they make ideal larval habitats," says Duane Gubler, a specialist in tropical medicine at Duke-NUS Medical School in Singapore. The insects also thrive in the water receptacles used by households without ready access to municipal services.

For one major vector-borne disease, urbanization actually provides some protection. The Anopheles mosquitoes that transmit malaria are much more particular about where they raise their young than Aedes. "They like clean, sunlit pools of water with vegetation around them, which are not typically found in urban areas," says ecologist and epidemiologist Andrew Tatem at the University of Southampton, UK. By combining detailed satellite data on urbanization in Uganda with household surveys for mosquitoes and data on malaria incidence, Tatem and his colleagues have observed a pattern (S. P. Kigozi et al. Malaria J. 14, 374; 2015). "It seems pretty clear that if you move to an urban area, you're at less risk of getting malaria," he says. There are some exceptions: gardens at the city edge can offer breeding grounds, and a species of malaria-transmitting mosquito (Anopheles stephensi) found in India can procreate in small water vessels much like Aedes can. "But in the concrete jungle, urban centre, you'll generally get zero breeding," says Mark Wilson, an ecologist and epidemiologist at the University of Michigan in Ann Arbor.

\section{NEIGHBOURHOOD WATCH}

The 2014 Ebola outbreak was a trial by fire, testing countries' capacity to deal with infectious disease. There was a stark divide between West African countries that promptly brought the epidemic under control and those that did not. Preparedness was a crucial distinguishing element, according to Breiman. Nigeria in particular benefited from a robust infrastructure for polio eradication, which was rapidly converted into a strategy for eliminating Ebola - the country was free of the disease after 3 months and 19 locally transmitted cases.

Such infrastructure is generally most developed in cities. Better community surveillance and prompt delivery of medical care are key advantages for battling the spread of infection. But even a well-designed rapid response can falter in the slums. Conakry established a dedicated Ebola-treatment centre within a month of the first reported case, but Sall and his colleagues encountered numerous hurdles among disenfranchised residents of the city's poorer districts. "People there tend to mistrust the government and the health system," he says. People kept their illness secret because they were afraid of being isolated from their families, and saw no value in reporting to a hospital if no cure was available. "Some people didn't want to go because they were worried about organ smuggling," says Sall. Fallah says that the situation was similar in Monrovia, with families performing secret - and unsafe - burials of their dead.

Grass-roots efforts made the crucial difference. The initial outbreak in Monrovia raged for months, but Fallah and his team regained control by conducting public meetings to discuss fears and concerns. "Many people brought very important suggestions, and this also brought us in touch with influential members of the 
community", he says. These connections helped track down slum-dwelling contacts who would otherwise have been missed. It also allowed the formulation of public-health practices that were compatible with the community's ethnic customs. "By getting engaged with religious leaders," says Fallah, "we developed methods to make burials safe while keeping them dignified."

\section{VANQUISHING VECTORS}

Community-centred strategies have not always been enough. Eliminating Aedes mosquitoes, for example, has often demanded aggressive government intervention. Beginning in the 1930s, US epidemiologist Fred Soper waged a successful war on dengue and yellow fever across Latin America - an effort facilitated by the dictatorial governments in power throughout the region. "The programme had a paramilitary type of structure," says Gubler. Soper and his team were given free rein to check every building in a city for mosquito habitats. In similarly heavy-handed fashion, Chile eliminated the Chagas vectors triatomines in its cities under the brutal regime of Augusto Pinochet with a door-to-door campaign overseen by the military police. "Insecticide sprayers would go to each house, and the carabineros would be with them," Levy says. "They'd ask if you'd let them in - and everybody said yes!"

Successful as these strategies may have been, the cost to personal liberty makes them impossible to endorse. Thankfully, in Arequipa, Levy and his Peruvian colleagues have made considerable progress through more reasonable means, particularly in poorer quarters where awareness of Chagas disease is high. Although in the richer districts, which have often had the luxury of ignoring the disease, the reception has been icier. Participation in the triatomine elimination campaign is $80-85 \%$ in poor districts, but only $64 \%$ in richer neighbourhoods. In

\section{"We still have} lots of epidemics of cholera in Africa, and these are typically associated with sanitation."

these communities,

says Levy, "the campaign has gone from being a wonderful public-health benefit to an imposition." His group is exploring incentives to boost participation, including community-leader training and raffles with jackpots that reflect the extent of the community's involvement.

Arequipa's triatomines are now largely under control, but vectors can quickly return if cities lower their guard. This is especially true of A. aegypti, because it procreates more rapidly and spreads more aggressively than triatomines. But convincing people to deal with the insects before they become a problem can be tough. As head of the US Centers for Disease Control and Prevention (CDC) dengue-control programme in Puerto Rico in the early 1980s, Gubler led a community-based effort to train residents to evict the mosquitoes from their back gardens.

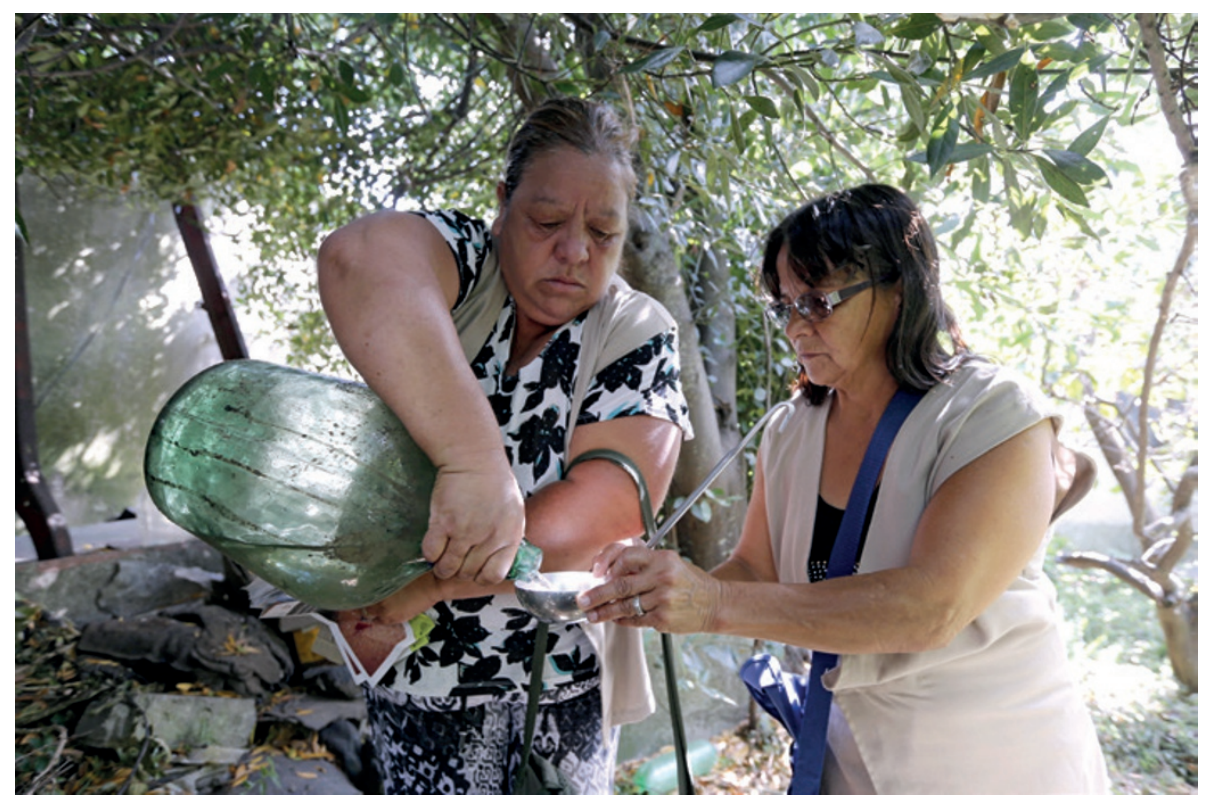

A water inspection to look for larvae of Aedes mosquitoes, which carry the Zika virus.

The results were disappointing. "Nobody controlled the mosquitoes in their yards or houses until there was an epidemic," he recalls. Ultimately, a multipronged attack may be the only real solution - thorough habitat eradication, sensitive diagnostics, access to durable insecticides and, ideally, a vaccine.

\section{A GLOBAL DIAGNOSIS}

Although slums provide fertile ground for infectious disease, the problem seldom remains local. Various species of Aedes mosquitoes have spread through the trade routes that link the world's cities. China's investment in urban development in Africa, for instance, has brought the Asian tiger mosquito Aedes albopictus to the continent. And once the Aedes mosquito makes itself at home, a sufficiently virulent strain of dengue can quickly cause a serious outbreak.

Outbreaks of dengue are facilitated by globalization. Singapore's anti-Aedes programmes, which were bolstered after a period of relaxation during the 1980s, have proved inadequate against introduction of the virus by visitors - including large numbers of migrant workers - from endemic regions in south and southeast Asia. A similar process allowed the Aedes-borne Zika virus, which was once confined to Asia and Africa, to establish itself in Brazil - one theory suggests that it may have arrived with the influx of tourists for the 2014 football World Cup. The virus has rapidly expanded its reach - the World Health Organization (WHO) is anticipating as many as 4 million cases throughout the Americas. "Zika virus has been around for many decades," says Riley, "but it wasn't until it entered massively urbanized Brazil that it spread like wildfire."

To prevent such propagation, the global public-health community must first intervene to protect the populations at the epicentres of emerging outbreaks. The Ebola epidemic served as an important call to arms. In Liberia, for example, what began as a crisis has turned into an opportunity to develop health-care capacity. "We have built up a competent corps of Liberians who understand the disease well," says Fallah. "We now have ambulances and contacttracers and lots of partners like CDC, WHO and Unicef working with us." Such efforts could dramatically reduce the severity of future outbreaks.

Nevertheless, the fundamental problem of the slums remains. "If we're going to prevent major epidemics," says Gubler, "we need better living standards - better housing, reliable piped water, good sewage and good hygiene in these tropical urban centres. That's not going to happen any time soon." Some governments have dealt with their slums by simply bulldozing them away. Others have pursued more sympathetic relocation programmes.

But community is essential to quality of life - especially for the urban poor - as Brazil discovered after it transplanted slum-dwellers to high-rises in the 1970s. The government provided a tremendous amount of new infrastructure, but the consequences were not all positive. "This just displaced the social network that these people had," says Riley. This upheaval "engendered crime and other disruption of the social fabric". Over the past decade, says Riley, Brazil's government has focused on improving the slums themselves, providing parks, childcare centres, electricity and drinkable water. In Fallah's view, recognizing this social fabric and partnering with the community leaders who bind it together offers the most cost-effective way to protect urban public health. "You have to have a consistent presence in the community, and not just a sporadic presence whenever there is an outbreak."

Michael Eisenstein is a freelance science writer in Philadelphia, Pennsylvania. 